\title{
Real-Time Signature Recognition Using Neural Network
}

\author{
Ahmed M. Alkababji \\ Ahmedalkababji72@uomosul.edu.iq \\ Ali Al-Saegh \\ ali.alsaegh@uomosul.edu.iq \\ M. F. Ghanim \\ mayada.faris@uomosul.edu.iq \\ Mohammad T. Mohammad \\ Mohammad.t.mohammad@uomosul.edu.iq \\ Computer Engineering Department, College of Engineering, University of Mosul
}

Received: 3/4/2021

Accepted: 6/5/2021

\begin{abstract}
The human signature is an important biometric feature that is used to identify human identity. It is essential in preventing falsification of documents in numerous financial, legal, and other commercial settings. The computerized system enters many aspects of our life, security is one of them, continues developing in computer vision and artificial network leads researcher to develop computerized signature recognition. This paper proposed a real-time algorithm for signature recognition. It is based on client and server operation.in which, client agent captures a signature and sends it to the server through the network. The server receives data and performs processing on it. Processing algorithm is based on weightless neural network. It is chosen for its simplicity and few numbers of sample required for training. The algorithm is tested and evaluated and show the ability to process 4.7 images per second.
\end{abstract}

Keywords:

Real-Time; Signature Recognition; Neural Network; Weightless neural network.

https://rengj.mosuljournals.com

Email: alrafidain_engjournall@uomosul.edu.iq

\section{Introduction :}

Technology development recently has contributed to digital devices to the escalating access and storage of confidential information. Therefore, the need for a more secure authentication mechanism becomes pressing and necessary [1]. Human signature confirmation frameworks stay up to present an acknowledged way for people to identify their personality in numerous application and regions. [2-3]. Computerized hand signature recognition strategies are divided into two main types dynamic recognition and static recognition [4]. Dynamic recognition verification based on biometric information that captures during human signature. like tracking human hand movement, the position of the pen, degree of pen slope, and etc. of the feature. Static recognition verification based on biometric information that captures after the human complete signature. Like finding the differences between signature in documents or identify the identity of the signature honor and etc. many papers presented in this field, each of them proposed a way to improve recognition. D. Moises in his paper assesses the signature recognition technology for the last 10 years [5]. Dipan Banerjee made a Survey for Offline Handwriting Signature Recognition technique [6]. Some researchers proposed a Signature Recognition System that is able to recognize signatures by using neural networks [7-11]. N. Abbas used histogram orientation gradient and support vector machine for signature recognition [1]. G. Nagaraj used fuzzy graph theory is used to analyze and identify the signature pattern [12].

Porwik and Para [13] adopted Hough transformation, center of gravity and horizontal and vertical histograms for extracting features. They used the formulated feature vectors for training a conventional neural network.

Pansare and Bhatia [14] used maximum horizontal and vertical histogram, center of mass, normalized 
area of signature, aspect ratio, tri surface feature, six fold surface feature, and transition feature for generating the feature vectors. They used a conventional neural network as a classifier.

In this research, an algorithm suggested for Real-time signature recognition.in which, weightless neural network (WNN) used for its flexibility, few training sample requirements. Besides these characteristics, feature vector selected to satisfy the requirement for real time. The paper is organized as follows: Section 2 artificial neural network, Section 3 system algorithms, Section 4 experimental setup, Section 5 Result, and Section 6 conclusion.

\section{Artificial Neural Network}

Those saying recognition assumes an import part of our daily life. It may be an essential property of human beings; The point when an individual sees an object, he alternately she gathers a data about the object like shape, color, size, features, and etc. all the data analyzed by mind searching for previous knowledge about the objects. if a proper match found then the object recognizes. Simulating those undertaking performed by human will make tremendously gainful to the computerized system. Based on this concept, the human neural system simulated in a computerized system using a neural network. In Artificial Network, every hub performs A percentage straightforward calculation Also every hub will be connected with each other. Every link labeled by a number known as "connection strength" alternately weight demonstrating that degree on [15].

The n-tuple classifier or RAM-based neural network deals with binary inputs and outputs type weightless artificial neurons connectors. The neurons could a chance to be envisioned Likewise look-up tables which mapping performs. WNN includes evolving the substance from claiming the individual's look-up tables instead of changing weights as in the classical model of the network. Thereby, RAMs are an essential part of building weight less network. Read and write operation latency is the most critical factors in neural work performance and also RAM makes learning time less than another type [16]. Learning network based on sets of logic functions developing to explain the matter. After learning, the neural network test stage performs to measure its ability to classify the input belongs to which classes and also there is no other class it belongs to them [17].

WNN network uses one-bit width Ram memory with variable location numbers based on the applications. Each ram connected for a decoder which addressed one location from the memory. Also, the control circuit to define memory state read or write. Write mode used during learning operations to change memory contents. Also, read mode used during testing and working mode.
Group of Rams memory connected to gather through adder to construct what names a discriminator as shown in Fig. 1. discriminator design based on the number of input pattern bit for the WNN. Number of RAMs in discriminator multiply by address bit number on it must equal number of pattern bit [18]. Each discriminator can classify one class. so, a number of discriminators in the designed $\mathrm{WNN}$ is equal to the number of the classes.

Several advantages make the application of WNN better than conventional NN are: its flexibility, the ease of design and implementation, fewer number of training samples is required. In addition to these characteristics, the proposed feature vector is easy to compute, has relatively reasonable size and differentiates among samples excellently [18].

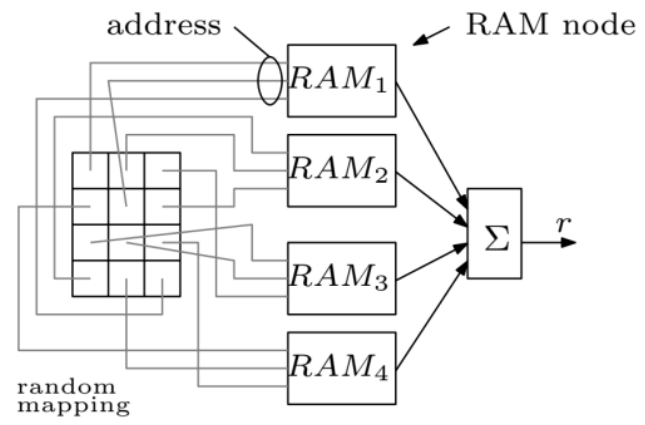

Fig. 1. Example of a Ram discriminator contains 4 memories [16].

At the learning stage, each discriminator RAMs works on write mode to modify contents. RAMs index decoder input connects to the input pattern base on biunivocal pseudo-random mapping.in the beginning, all the RAMs fill by logic ' 0 '.For every training input pattern, the pointed locations in RAMs will change the contain from ' 0 ' to ' 1 '. this operation performed to all training pattern to create a discriminator that has memory with special combination of ' 0 ' and ' 1 '. the operation is repeated to all discriminator in the network but by a different training input class. Each discriminator is trained for one class classification. As an example, a system to classify five objects so WNN required five discriminators for this operation.

At the testing stage, each discriminator RAMs works on reading mode. The network uses the special combination of ' 0 ' and ' 1 ' that created during the training stage to classify unseen pattern.at any time new pattern input to the network, this pattern address RAMs in all the discriminators in the network. For each discriminator, discriminator response calculated by summing the output of Rams. Different special combination memory contents of RAM will result in different discriminator response. Based on this, networks can classify objects to determine the 
know it or not. Value of $r$ range between zero as a minimum and $\mathrm{M}$ (number of RAM) as a maximum. When response equal to zero this mean there is no similarity. On the other hand, response equal to $\mathrm{M}$ this means identical to the class.so, $r$ value measures the similarity between the input pattern and the learned pattern in the network compare the value for $r$ in each discriminator and pick the maximum of them. Then, the pick one compared with the threshold value to determine the right of the classification. If it greater than the threshold the object classifies and belongs to the discriminator class with the greatest response.in contrast if less than then the object not classify or the network not trained to classify it.

It is obvious that $\mathrm{WNN}$ is facile to design and implement because it requires a collection of slices and counters only. On the other hand, Conventional ANNs are more intricate as they require a number of mathematical operation in order to handle the connectors weights and calculate neurons threshold.

Furthermore, the training process in WNN is fast and easy compared with the conventional neural network. Where training in WNN just fills RAM memory with the pattern. But the conventional neural perform continues update weight until found the suitable weight.

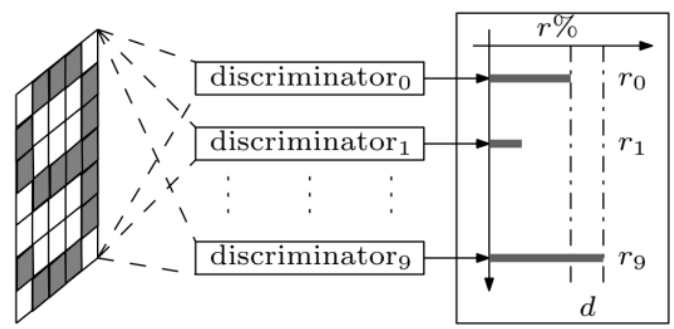

Fig. 2. Example of a weightless neural network consists of number of discriminators [16].

\section{System Algorithms}

The implementation of the system is divided into two parts training algorithm and real-time recognition algorithm. Each of them performs starting by performing the preprocessing operation and feature extraction.

Preprocessing operation performs on any images entered into the system. they work to enhance images, remove noise and unified the data size. Moreover, these operations eliminate the problem of different pen head size with the same person signature. There are three operations perform in this step.

First, image binarization in which a settled limit T esteem to utilized to select out 0 's and 1's for all pixel positions in a given picture. The fundamental thought for settled binarization strategy is to describe as beneath [19].

$$
g(x, y)=\left\{\begin{array}{l}
1 \text { if } f(x, y)>=T \\
0 \text { otherwise }
\end{array}\right.
$$

Second, Image resizes to unified the size of data perform enter to the algorithm. Third, Thinning performs on all the images to make sure that the signature with the different pen has the same data pattern. This operation made the line width one-pixel only. as shown in Fig. 3.

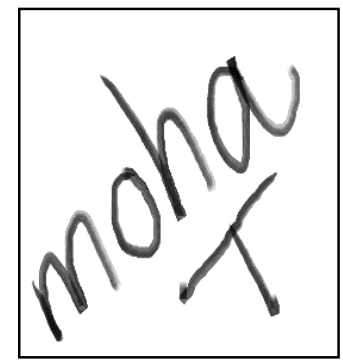

(a)

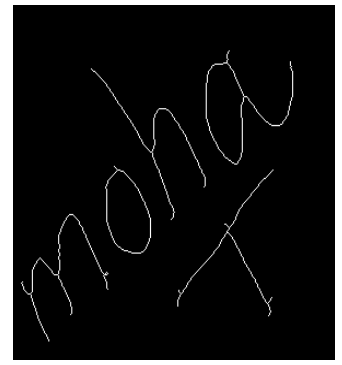

(b)
Fig. 3. (a) Image before preprocessing, (b) Image after preprocessing.

Feature extraction is the method of describing the input signature image in numeric values, it is essential to diminish the amount of information which can be processed by the classifier. Selecting features from image got high interesting by the researcher [7-11]. This paper used four types of features that have been improved for their simplicity and efficiency in recognition [18].

\section{Horizontal Grids}

This feature based on dividing the image into four horizontal segments. Then calculate a number of white pixels inside the segment. This feature produces four numbers for each segment.

\section{Vertical Grids}

This feature based on dividing the image into 64 Vertical segments. Then calculate a number of white pixels inside the segment. This feature produces 64 numbers for each segment.

\section{Horizontal Rectangular Grids}

This feature based on dividing the image into 256 Horizontal Rectangular segments. Then calculate a number of white pixels inside the segment. This feature produces 256 numbers for each segment.

4. Vertical Rectangular Grids 
This feature based on dividing the image into 256 Vertical Rectangular segments. Then calculate a number of white pixels inside the segment. This feature produces 256 numbers for each segment.

All the features normalize individually between 0 to 1 and then round to 0 or 1 . The final feature vector is equal to 580 values for every image. Features grids shown in Fig. 4.

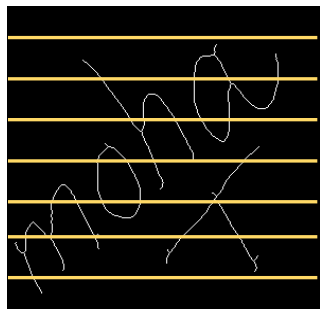

(a)

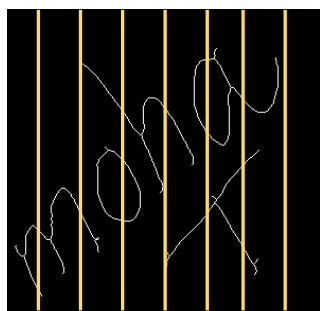

(c)

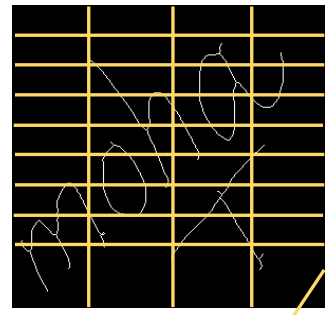

(b)

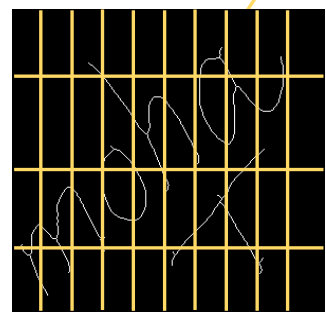

(d)
Fig. 4. (a) Horizontal Grids, (b) Horizontal Rectangular Grids, (c) Vertical Grids and (d) Vertical Rectangular Grids.

\section{A) Training Algorithm}

A weightless neural network trained by a number of signature images for each different user. For each different signature, Discriminator mast added in the neural network during the training. The algorithm must reperform every time when a new signature added. the algorithm performs the following steps.

1) Read training images for every signature.

2) Perform pre-processing operation for all Images.

3) Perform Feature Extraction for all Images.

4) Construct a Feature Vector for all images.

5) Train WNN (RAM on Write mode).

a) Assuming discriminator for each user signature.

b) Randomly distribute the elements of vectors features of each different signature in the table.

c) place " 1 " in a location addressed by the address decoder.

6) Repeat (5) until all the signature presented in the neural network.

B) Real-Time Recognition Algorithm

The algorithm starts with image capturing. The mobile phone used for this aspect.it must contain "IP webcam" that provides an IP address for mobile camera. IP used to be the server (PC) to communicate with mobile and receive image wirelessly. Image enter preprocessing operation (Binarization, Image resize, and Thinning). Feature extraction performs to calculate the feature. Normalize and rounding perform to calculate the feature vector. Trained weightless neural network used to classified the signature. If the response of the neural network less than the threshold then the signature not classified. On the other hand, the signature detected then the discriminator with the highest response the signature belongs to it. the algorithm is shown in Fig. 5.

\section{Experimental Setup}

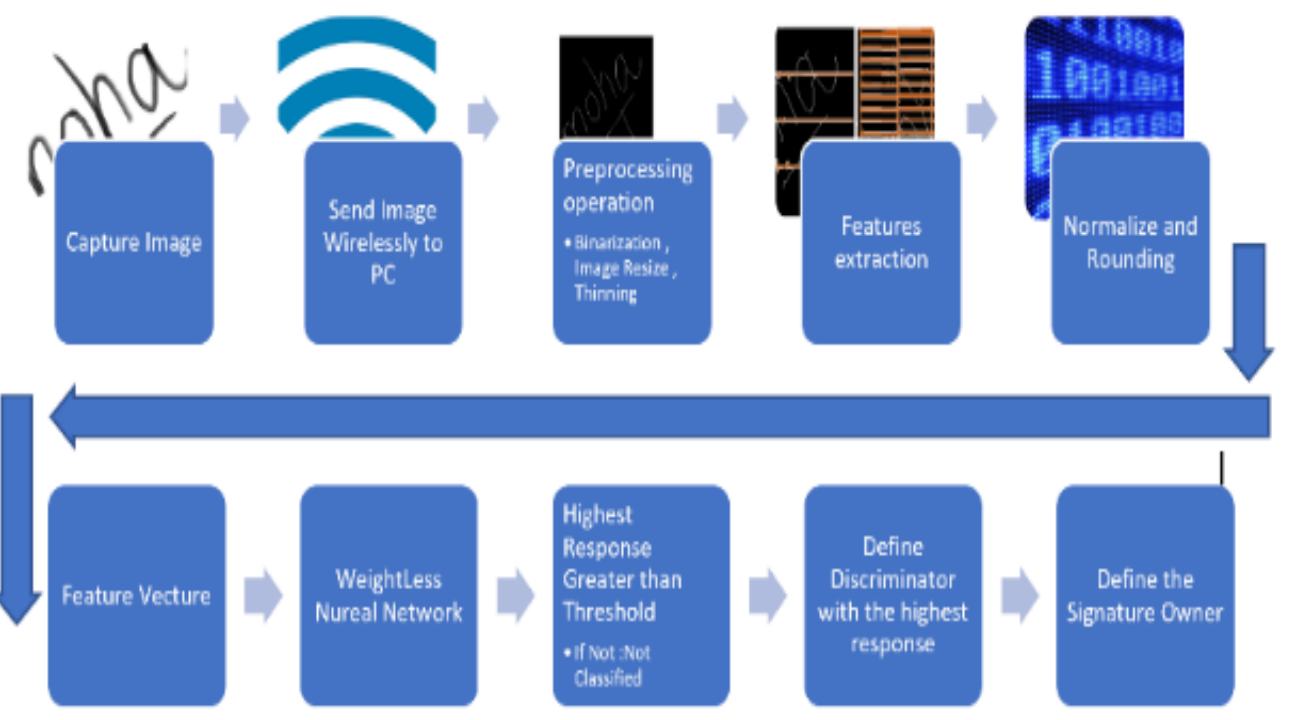

Fig. 5 Real time recognition algorithm. 
The signatures used in this paper based on the database of "ICDAR 2011 Signature Verification Competition (SigComp2011)". Free database available Online on the internet.

"IP WebCam" application freely available at the Android store.it used to provide an IP address for the mobile camera.

IP V4 router with $100 \mathrm{Mbps}$ used to provide communication between mobile and Pc.

Pc used as a server for processing the data. It specifies by Core I7, 16 Gbyte Ram, and SSD Hard.

The mobile phone as a client to capture an image. It specifies by Hisilicon Kirin 970 and 6 GB RAM.

\section{Experimental Results}

The algorithm capability to perform realtime recognition tested and evaluated as follow.To test algorithm, a neural network trained with 40 different signatures with 5 images for each. The algorithm executed on $\mathrm{pc}$ as a server and mobile as a client. The algorithm shows a capability to process at an average 4.7 image/sec.in each process all the algorithm execute and classify the signature. Processing rate depends on two factors, Communication delay, and processing delay. Signature recognition rate in the idle case without using the Mobile phone for image capture 99.67 and rejection rate $99.55 \%$ but these rates got difference using real-time capture using a mobile phone. This back for many reasons. first, mobile camera resolution difference from database Scanner images. second, camera focus. Third, the type of lens. Fourth, camera noise. Last, surrounding light at image capture this is the most critical factor in the operation. Sometimes due to the lighting, most of the data got lost as shown in Fig 6.

Table1 summarizes the attained results of some works and the proposed work. It is clear that our proposed work has achieved better recognition rate in comparison to other works.

The rate got close to $99.55 \%$ when we consider the five criteria mentions before. And, the rate got declined depends on the criteria strength. All of this shows the success of the system and the capability of weightless neural network with this type of features to work as real-time recognition.
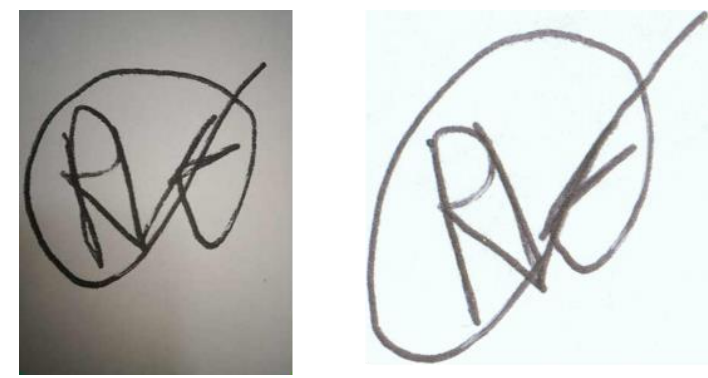

(a)

(b)

Fig 6: (a) Signature capture by mobile camera.

(b) Signature selected from ICDAR library.

Table 1

A comparison between the proposed signature recognition system and other work

\begin{tabular}{|c|c|c|c|c|}
\hline $\begin{array}{c}\text { Author \& } \\
\text { reference }\end{array}$ & Classifier & $\begin{array}{c}\text { Recognition } \\
\text { rate }(\%)\end{array}$ & $\begin{array}{l}\text { Real time } \\
\text { Capability }\end{array}$ & Environment \\
\hline $\begin{array}{c}\text { Porwik and } \\
\text { Para [13] }\end{array}$ & $\begin{array}{c}\text { Combined } \\
\text { method } \\
\text { with Hough } \\
\text { transformati } \\
\text { on }\end{array}$ & 94.60 & $\begin{array}{l}3.3 \text { image } \\
/ \mathrm{sec}\end{array}$ & $\begin{array}{l}\text { PC AMD } \\
\text { Athlon } \\
1.91 \mathrm{GHz}, \\
\text { RAM } \\
512 \mathrm{MB}\end{array}$ \\
\hline $\begin{array}{c}\text { Pansare and } \\
\text { Bhatia [14] }\end{array}$ & $\begin{array}{c}\text { Back } \\
\text { propagation } \\
\text { NN }\end{array}$ & 82.60 & $\begin{array}{c}\text { Not } \\
\text { mentioned }\end{array}$ & $\begin{array}{c}\text { Not } \\
\text { mentioned }\end{array}$ \\
\hline $\begin{array}{c}\text { Darwish } \\
\text { and Auda } \\
\text { [20] }\end{array}$ & $\begin{array}{c}\text { Fast back } \\
\text { propagation } \\
\text { NN }\end{array}$ & 98.60 & $\begin{array}{c}\text { Not } \\
\text { mentioned }\end{array}$ & $\begin{array}{c}\text { Not } \\
\text { mentioned }\end{array}$ \\
\hline \multirow{3}{*}{$\begin{array}{l}\text { Ubul et. al. } \\
\text { [21] }\end{array}$} & $\begin{array}{c}\text { Euclidean } \\
\text { distance } \\
\text { (ED) } \\
\end{array}$ & 86.45 & \multirow{3}{*}{$\begin{array}{c}\text { Not } \\
\text { mentioned }\end{array}$} & \multirow{3}{*}{$\begin{array}{c}\text { Not } \\
\text { mentioned }\end{array}$} \\
\hline & $\begin{array}{l}\text { K-nearest } \\
\text { neighbor } \\
(\mathrm{K}-\mathrm{NN})\end{array}$ & 93.53 & & \\
\hline & Bayes & 89.26 & & \\
\hline $\begin{array}{l}\text { Proposed } \\
\text { work }\end{array}$ & $\begin{array}{c}\text { Weightless } \\
\text { neural } \\
\text { network } \\
\text { (WNN) }\end{array}$ & 99.67 & $\begin{array}{c}4.7 \\
\text { image/sec }\end{array}$ & $\begin{array}{c}\text { Server + } \\
\text { Client }\end{array}$ \\
\hline
\end{tabular}

\section{Conclusion}

Real-time static signature recognition system has been designed based on a weightless neural network. It is chosen for its simplicity and without need for update weight like a classical neural network. The proposed system work as client and server where client capture image and server process it. The processing algorithm starts by preprocessing then feature extraction and last recognition. The algorithm test and evaluate their ability to work in real time.

\section{References}

[1] N. Abbas, K. N. Yasen, K. Faraj, L. A. Razak, F. Malallahf, "Offline Handwritten Signature Recognition Using Histogram Orientation gradient and Support Vector Machine", Journal of Theoretical and Applied Information Technology", Vol.96. No. 8 pp.2075-2084, 2005.

[2] R. Plamondon and S. N. Srihari, ,"On-line and off-line Handwriting Recognition: A comprehensive survey", IEEE Transactions on Pattern Analysis and Machine Intelligence, Vol. 22, pp. 63-84, 2000. 
[3] L. Batista, D. Rivard, R. Sabourin, E. Granger, and P. Maupin, "State of the art in off-line signature verification", Pattern Recognition Technologies and Applications: Recent Advances, pp. 39-62, 2008.

[4] A. Bharadwaja, "The Analysis of Online and Offline Signature Verification Techniques to Counter Forgery", Indian Journal of Science and Technology, Vol 8(20). 2015

[5] D. Moises, M. Ferrer, D. Impedovo, M. Malik, G. Pirlo and R. Plamondon, "A Perspective Analysis of Handwritten Signature Technology", ACM Computing Surveys, Vol. 51, pp. 1-39, 2019

[6] B. Dipan, \& D. Kinjal, G. Debayan and C. Kingshuk, "A Survey of Offline Handwriting Signature Recognition", International Conference on Emerging Technologies for Sustainable Development - ICETSD '19.

[7] N. Rasheed, "signature recognition using neural network", Computer Science Dept., the military college. Thesis, 2002.

[8] G. Khuwaja, " Offline Handwritten Signature Recognition", World. Academy of Science, Engineering and Technology, vol. 59, pp. 1300-1303,2011.

[9] A. Karouni, B. Daya,S. Bahlak, "Offline signature recognition using neural networks approach", Procedia Computer Science Vol.3, pp.155-161, 2011.

[10] Y. Laila and B. Ahmed, "Off-Line-SignatureRecognition-Based-On-Angle-Features-andGRNN-Neural-Networks", International Journal of Computer and Information Sciences. Vol.7, pp.229-233, 2013.

[11] S. Sthapak, M. Khopade and C. Kashid, "Artificial Neural Network Based Signature Recognition \& Verification", International Journal of Emerging Technology and Advanced Engineering, Vol. 3, No. 8,pp.2-7 2013.

[12] N.Gayathri, A. Irin Feno, T. Keerthana N. Gayathri, "Signature Recognition using Fuzzy Graph Theory",International Journal of Scientific Development and Research, Vol.4, No.3, pp.21-27,2019.
[13] P. Porwik and T. Para, "Some Handwritten Signature Parameters in Biometric Recognition Process," in International Conference on Information Technology Interfaces, Croatia, 2007, pp. 185-190.

[14] A. Pansare and S. Bhatia, "Handwritten Signature Verification using Neural Network," International Journal of Applied Information Systems (IJAIS), vol. 1, pp. 44-49, 2012.

[15] C.Patel, R. Patel , "Handwritten Character Recognition using Neural Network" International Journal of Scientific \& Engineering Research, Vol. 2, No.5,2011.

[16] I. Aleksander, M. De Gregorio, F. M. G. Franca, P. M. V. Lima, and H. Morton, "A Brief Introduction to Weightless Neural Systems", 17th. European Symposium on Artificial Neural Networks , 2009.

[17] J. Austin, "A Review of RAM Based Neural Networks,", Microelectronics for Neural Networks and Fuzzy Systems, pp. 58-66,1994.

[18] Ali Al-Saegh, "Off-line Signature Recognition Using Weightless Neural Network and Feature Extraction", Iraq J. Electrical and Electronic Engineering, Vol.11 No.1, 2015.

[19] Puneet, Naresh Garg, "Binarization Techniques used for Grey' Scale Images", International Journal of Computer Applications, Vol. 71, No.1, 2013.

[20] A. M. Darwish and G. A. Auda, "A New Composite Feature Vector for Arabic Handwritten Signature Recognition," in International Conference on Acoustics, Speech, and Signal Processing, Australia, 1994, pp. II-613.

[21] K. Ubul, A. Adler, G. Abliz, M. Yasheng, and A. Hamdulla, "Off-line Uyghur Signature Recognition Based on Modified Grid Information Features," in International Conference on Information Science, Signal Processing and their Applications, Canada, 2012, pp. 1056-1061. 


\section{تمييز التواقيع في الزمن الحقيقي باستخدام الثبكات العصبية}

ميادة فارس غانم

mayada.faris@uomosul.edu.iq

محمد طارق محمد

mohammad.t.mohammad@uomosul.edu.iq
احمد مامون الكبابجي

ahmedalkababji72@uomosul.edu.iq

علي مخلف الصائغ

ali.alsaegh@uomosul.edu.iq

$$
\text { جامعة الموصل ـ كلية الهندسة ـ قسم هندسة الحاسوب }
$$

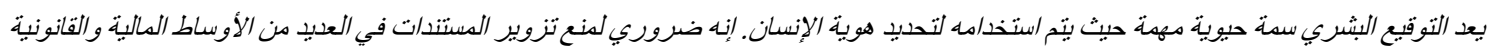

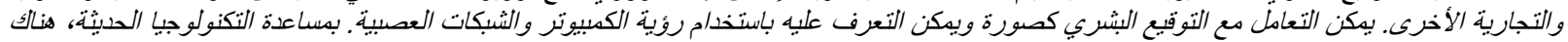

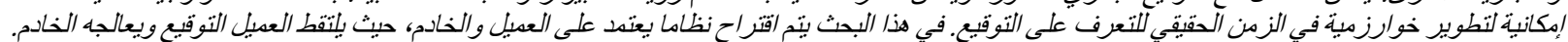

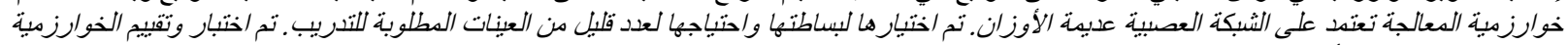
وتبين من النتائج العطلية أن هناك قدرة على معالجة 4.7 صورة في الثانية.

الكلمات الدالة: الزمن الحقيقي، تمييز التو اقيع، الثبكات العصبية، الثبكة العصبية عديمة الأوزان. 